\title{
Role of Percutaneous Disc Decompression using Coblation in Managing Chronic Discogenic Low Back Pain: A Prospective, Observational Study
}

\author{
Vijay Singh, MD, Chandur Piryani, MD, and Katherine Liao, MD
}

\begin{abstract}
Background : Percutaneous disc decompression using Coblation (Nucleoplasty ${ }^{\mathrm{TM}}$ ) implements the principle of volumetric reduction to achieve disc decompression and reduce intradiscal pressure. Previous analyses have shown that Nucleoplasty achieves reduction in volume and intradiscal pressure with minimal damage to surrounding tissue in the treated disc.

Objective : To determine effectiveness of nucleoplasty in patients with discogenic back pain.

Study Design: A prospective, non-randomized, observational study.

Methods: Forty-seven patients presenting with predominant back pain undergoing treatment with the Nucleoplasty procedure
\end{abstract}

Chronic low back pain is a complex clinical problem with multi-faceted etiology. The inability of diagnostic techniques to isolate a specific site or structure as the origin of pain has made it a consistently difficult condition to treat effectively. A combination of multiple structural and biochemical origins of low back pain may be associated with or exacerbated by degeneration or herniation of the disc.

The intervertebral disc plays a pivotal role in the production of low back pain. Anatomically, the disc appears to be a simple structure though physiologically it is one of the largest avascular structures in the body, with complex biochemical func-

From Pain Diagnostic Associates, Niagara, Wisconsin.

Address Correspondence: Vijay Singh, MD, Pain Diagnostics Associates, 1601 Roosevelt Road, Niagara WI 54151

Support: Facilities and personnel were provided by Pain Diagnostics Associates, Niagara, WI.

Conflict of Interest: None

Disclaimer: There was no external funding in preparation of this manuscript.

Acknowledgement: Manuscript received on 1/6/04. First revision submitted on 4/10/04

Second revision submitted on $8 / 17 / 04$

Accepted for publication on $8 / 23 / 04$ using Coblation technology were included in this analysis. Patients were followed at 1 month, 3 months, 6 months, and 12 months after the procedure.

A numeric pain scale of o to 10 , percent pain relief, and improvement in functional status as determined on the basis of their ability to sit, stand, and walk.

Results: The proportion of patients who reported $50 \%$ or more pain relief was $80 \%, 74 \%, 63 \%$ and $53 \%$ at the $1,3,6$ and 12 months follow-up time periods, respectively. Functional improvements were reported by $46 \%$ of patients for sitting ability, $41 \%$ for standing ability, and $49 \%$ for walking ability at 12 months. There were no complications observed due to the $\mathrm{Nu}$ - cleoplasty procedure.

Conclusion:Nucleoplasty for disc decompression is one of the least-invasive techniques in the minimally invasive category, thus far exhibiting a very low incidence of complications. Although no long-term data are available, these preliminary results indicate that the Nucleoplasty procedure is a safe and moderately effective procedure for reducing pain in patients presenting with predominant discogenic low back pain associated with contained disc herniation.

Keywords: Low back pain, percutaneous disc decompression, nucleotomy, coblation, nucleoplasty, radiofrequency

tion. Due to its location, the disc is susceptible to injury, which often precipitates a cascade of painful sequelae such as internal disc disruption, disc degeneration, and disc herniation (1-4). Pain generation may occur with activation of pain receptors within the disc itself or with chemical irritation (5) and/or mechanical compression (6) of surrounding spinal structures such as the posterior longitudinal ligament, the dorsal root ganglion (DRG), the nerve root, the spinal cord, and the cauda equina (7-9).

Treatment of discogenic low back pain has been evolving for centuries, though the most significant advancements occurred after Mixter and Barr, in 1934 (6), published that the disc itself could cause low back pain and sciatica. Despite the abundance of surgical and minimally invasive treatments available, few studies have validated the treatment of chronic discogenic low back pain associated with contained disc herniation that has failed to improve with comprehensive, non-operative care. Carragee et al $(10,11)$ demonstrated that though open surgical discectomy is effective for large herniations of over $9 \mathrm{~mm}$, they have not been demonstrated effective for small, contained herniations of less than $6 \mathrm{~mm}$. Minimally invasive surgical interventions have become an option for these patients, providing an effective treatment modality for pain relief from chronic back pain.

In the 1950's the era of percutaneous disc decompression was ushered with the availability of the enzyme chymopapain for chemonucleolysis. Studies analyzing the use of chymopapain have indicated success rates as high as $89 \%$ (12); the enzyme has become unavailable in the United States. Though alternative chemicals are under investigation for use in these procedures (13), chemonucleolysis remains uncommon within the U.S. Historically, indications for the chemical method of disc decompression have not included axial back pain patients, but have instead been used primarily for patients with sciatica or radicular symptoms associated with mechanical compression. Additionally, a leaking disc (as confirmed by discography) is considered a contra-indication for this procedure, as injecting an inflammatory chemical agent such as chymopapain can potentially lead to serious complications, such as myelop- 
athy $(14,15)$.

Manual and automated mechanical disc decompression procedures have been primarily for disc herniation with radicular pain, usually with a positive straight leg raise test and positive neurological signs $(16,17)$. Indications for the manual and automated methods of disc decompression have not historically included axial back pain patients, though an analysis of both procedures has indicated a good to excellent outcome for $63 \%$ and a fair outcome for $20 \%$ of chronic back pain patients (18). Further, percutaneous laser disc decompression (PLDD) for back pain has been reported to be effective in 52 to $60 \%$ of the patients (19-22). In addition, good to fair response using percutaneous disc decompression techniques for the treatment of pain associated with small, contained herniated discs, specifically discs in the lumbar region has been reported (23).

Since the introduction of Coblation technology for disc decompression, several short-term analyses of the Coblation procedure have been conducted for patients presenting with back and/or leg pain. Sharps et al (24) analyzed 49 patients for 3-12 months, with 13 patients followed for 1 year, reporting that $79 \%$ of patients indicated a VAS reduction of 2 or more. Singh et al (25) analyzed 67 patients with 41 followed for 1 year, reporting that $80 \%$ of patients indicated significant improvement in numeric pain scores with $59 \%$ reporting a numeric pain score reduction of 2 or more. Additionally, significant functional improvement was reported by $62 \%$ of patients in sitting, 59\% in standing, and $60 \%$ in walking ability.

More recently laser disc decompression and Coblation have been used in clinical practice for patients presenting primarily with back pain. However no published clinical research has examined the effect of percutaneous plasma discectomy on primary discogenic back pain. In light of this lack of evidence, and recent advances in the understanding of the tissue effects of Coblation on the nucleus, this single site analysis was conducted to evaluate the effectiveness of the Coblation procedure for the treatment of discogenic back pain.

\section{Methods}

An outcome analysis was prospectively conducted for up to 1-year postNucleoplasty.

\section{Informed Consent}

The nature of this study and the associated risks were explained to all subjects along with an opportunity to ask questions and decide whether or not they wanted to participate. Informed consent was obtained. Appropriate precautions were taken to protect the anonymity and privacy of the patients participating in this study.

\section{Inclusion Criteria}

Discogenic low back pain confirmed by discography, lack of response to three or more months of conservative management (including fluoroscopically directed injection therapies), absence of neurologic deficit, average pain of at least 5 or greater, and positive provocative discography based on the International Association for the Study of Pain (IASP) criteria (26) with elicitation of concordant pain and identification of at least one negative control disc.

\section{Exclusion Criteria}

Litigation, heavy opioid usage, uncontrolled psychological disorders, evidence of infection or spinal instability, disc herniation with sequestration, large contained herniation occupying onethird or more of the spinal canal, nonqualifying results on provocative discography, or marked spinal stenosis due to extensive osteophyte formation.

\section{The Coblation Procedure}

The percutaneous disc decompression procedure was performed in the operating room under conscious sedation and fluoroscopic guidance while the patient was in a prone position. A 17-gauge, six-inch long spinal cannula provided minimally invasive access to the junction of the nucleus and annulus. A uniportal approach was used to access the disc from the side of predominant pain. An ablation and coagulation spine wand was introduced through the access cannula intradiscally. A channel was created within the nucleus by advancing the wand, in ablation mode, at a speed of $0.5 \mathrm{~cm} / \mathrm{sec}$ and retracting the wand in coagulation mode at the same rate. Decompression was accomplished by creating six channels. All patients received either intradiscal antibiotics prior to removal of the access cannula or prophylactic intravenous antibiotics (most patients received both).

\section{Post-operative Care}

Patients were discharged the same day. Postoperatively, patients were instructed to perform limited daily living activities as needed with restriction of bending and stooping and no lifting of over 10 pounds for 2 weeks. After two weeks, patients were permitted to return to sedentary or light work and were provided with home exercise instructions.

\section{Outcome Measures}

Patient's self report of severity of pain on a numeric pain scale of 0 to 10 (with 0 being no pain and 10 being the most severe pain) and percent of pain relief were utilized to determine pain levels. Improvement in functional capacity was calculated based on patients reported ability to sit, stand, and walk, dividing them into the following sub-categories: less than $15 \mathrm{~min}$., 15 to $30 \mathrm{~min}$., 31 to 45 min., $45 \mathrm{~min}$. to $60 \mathrm{~min} ., 1$ to 2 hours, and greater than 2 hours.

\section{Statistical Analysis}

Pre- and post-treatment means, ranges, and standard deviations (SD) were calculated. For outcomes and nonparametric values, 95\% confidence intervals and paired t-test were used to compare pre- and post-treatment pain scores. Results were considered statistically significant if the $p$-value was less than 0.05 for continuous variables.

\section{RESULTS}

\section{Patient Follow-Up}

Patient demographics are illustrated in Table 1.

Of the total 47 patients undergoing Nucleoplasty, five patients had suffered re-injury or a new injury due to a fall within 3 months of the procedure, undergoing additional treatment. Five patients were lost to follow-up due to relocation. Thus, data were reported 46 patients at 1 month, 42 at 3 months, 40 at 6 months, and 37 at one year.

\section{Pain Reduction}

Fig. 1 illustrate changes in numeric pain score from baseline to 12 months evaluation.

Based on criteria of significant pain relief ( $50 \%$ or more pain relief) the proportion of patients in this category were $80 \%, 74 \%, 63 \%$ and $53 \%$ at $1,3,6$ and 12 
Table 1. Demographic characters for the 47 patients who underwent the percutaneous disc decompression procedure for primary axial low back pain

\begin{tabular}{|l|l|c|}
\hline \multirow{2}{*}{ Gender } & Male & $32 \%(15)$ \\
\cline { 2 - 3 } Age (Years) & Female & $68 \%(32)$ \\
\hline \multirow{2}{*}{ Onset of Pain } & Mean \pm SD & $44 \pm 11$ \\
\cline { 2 - 3 } & Range & $15-62$ \\
\hline \multirow{2}{*}{$\begin{array}{l}\text { Duration of Pain } \\
\text { (Years) }\end{array}$} & Traumatic & $13 \%(6)$ \\
\cline { 2 - 3 } & Non-traumatic & $87 \%(41)$ \\
\hline Height (Inches) & Mean \pm SD & $6.3 \pm 6.0$ \\
\hline \multirow{2}{*}{ Smoking Habits } & Range & $0.5-29$ \\
\hline \multirow{2}{*}{ Decompression } & Mean \pm SD & $67 \pm 4.6$ \\
\hline Previous Discectomy & Nonsmoking & $68 \%(32)$ \\
\cline { 2 - 3 } & Smoking & $32 \%(15)$ \\
\cline { 2 - 3 } & Single level & $81 \%(38)$ \\
\hline
\end{tabular}

months, respectively (Fig. 2).

\section{Functional Outcomes}

Significant functional improvement was seen for sitting $(p=0.02)$ and walking ( $p=0.02)$, though not for standing $(p=0.09)$ (Fig. 3). At 1 year, 32\%, 30\%, and 35\% of patients reported an ability to sit, stand, and walk for more than 2 hours, respective- ly, as compared to baseline reports by $11 \%$, $13 \%$, and $15 \%$ of patients (Fig. 4 ).

\section{Complications}

There were no complications, including discitis or neurological deficit related to the procedure.

\section{DISCUSSION}

This prospective evaluation of $47 \mathrm{pa}-$ tients undergoing Nucleoplasty for predominantly low back pain demonstrated significant pain relief, defined as $50 \%$ or more relief, in $63 \%$ of the patients at 6 months and $53 \%$ of the patients at 1 year. This evaluation also showed functional improvements for sitting, walking, and sustained activity of 2 hours or longer. However, improvement was not noted in the capacity for standing. The results are clinically significant as the patients involved in this analysis were unable to improve with conservative therapies including physical therapy, activity modification, drug therapy, and fluoroscopically guided epidural steroid injections. In addition, approximately $80 \%$ of patients suffered with chronic pain of 2 years or longer. All the patients were non-surgical candidates. Thus, the only treatment alternatives for these patients were limited to chronic drug therapy and/or minimally invasive interventions such as percutaneous disc decompression. Percutaneous disc decompression was preferred by the patients chosen for this survey over prolonged medical management with continued pain and dysfunction (27). Thus, in patients with long-term chronic low back pain without radicular symptoms or signs, with contained disc herniation, nucleoplasty, a minimally invasive technique

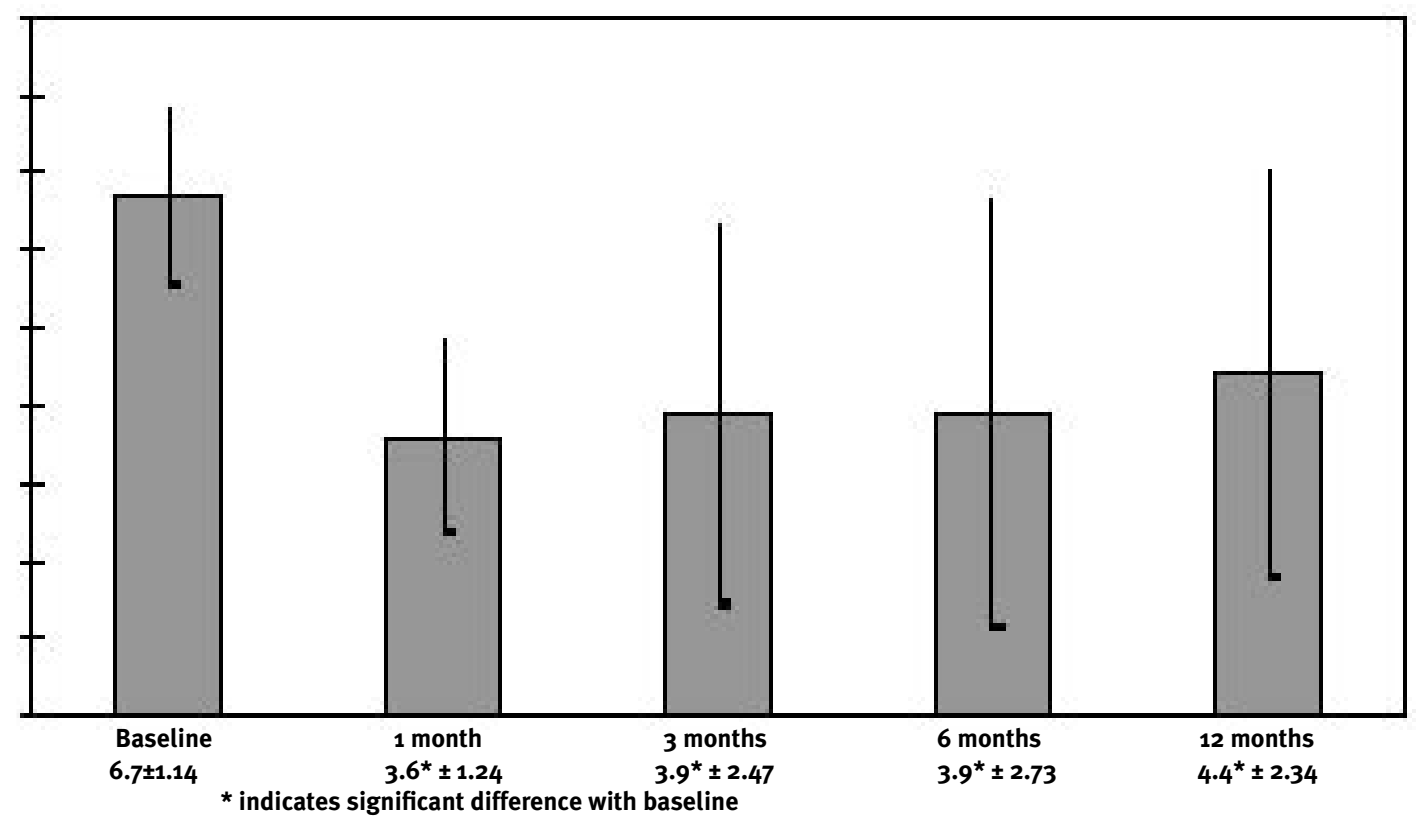

Fig 1. Outcome measurements (Mean $\pm S D$ ) based on Visual Analog Scale Report 


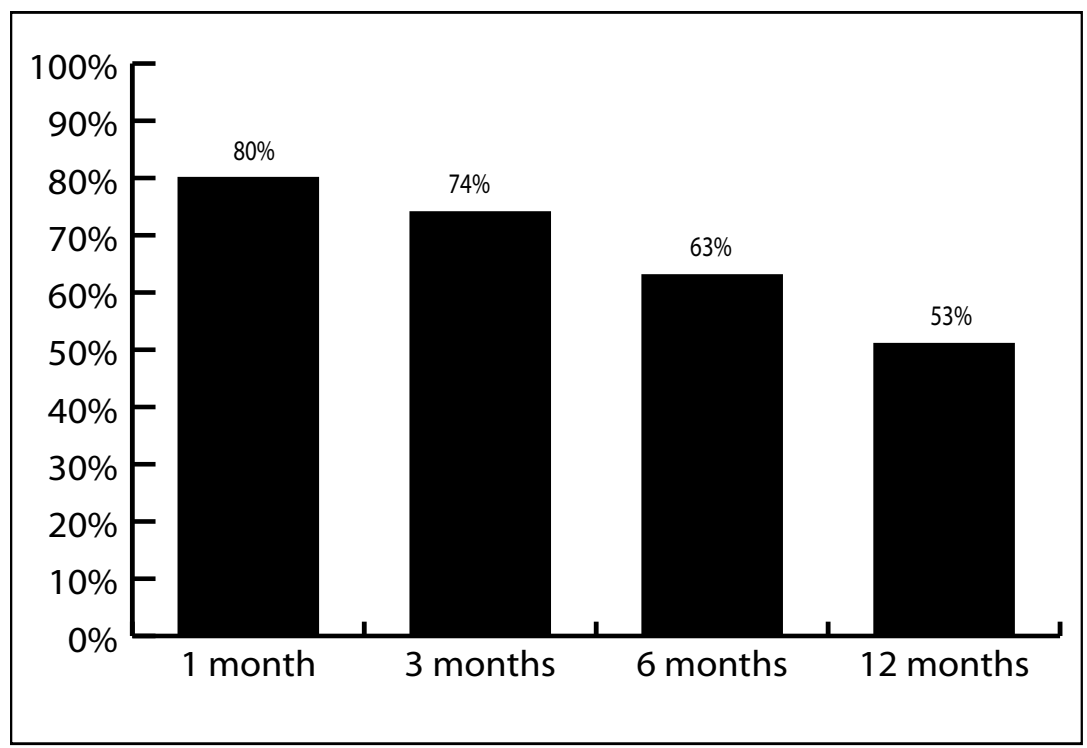

Fig. 2. Proportion of patients reporting significant ( $\geq 50 \%)$ pain relief

for percutaneous disc decompression utilizing Coblation, presents not only an alternative modality, but also provides an encouraging outlook.

The proportion of patients with more than $50 \%$ pain relief declined at 12 months, from a high of $80 \%$ at 1 month to $53 \%$ at 12 months. However, this is also observed following all types of interventions in managing low back pain, both surgical and non-surgical $(10,28,29)$. This may be related to the intricate metabolic function of the intradiscal matrix, which is highly sensitive to biochemical changes related to in- tradiscal pressure, rather than a treatment modality applied. Further, reestablishment of the delicate balance of nutritional exchange within the disc impacts the synthesis and breakdown of the intradiscal matrix $(30,31)$. Nucleoplasty theoretically allows reestablishment of normal nutritional exchange by achieving a reduction in volume, which in turn, causes a reduction in intradiscal pressure. Though the treatment may initially restore normal physiological function to the matrix, further injury, whether due to trauma, aging, or disease, may hinder or reverse the effects with time. Ongo-

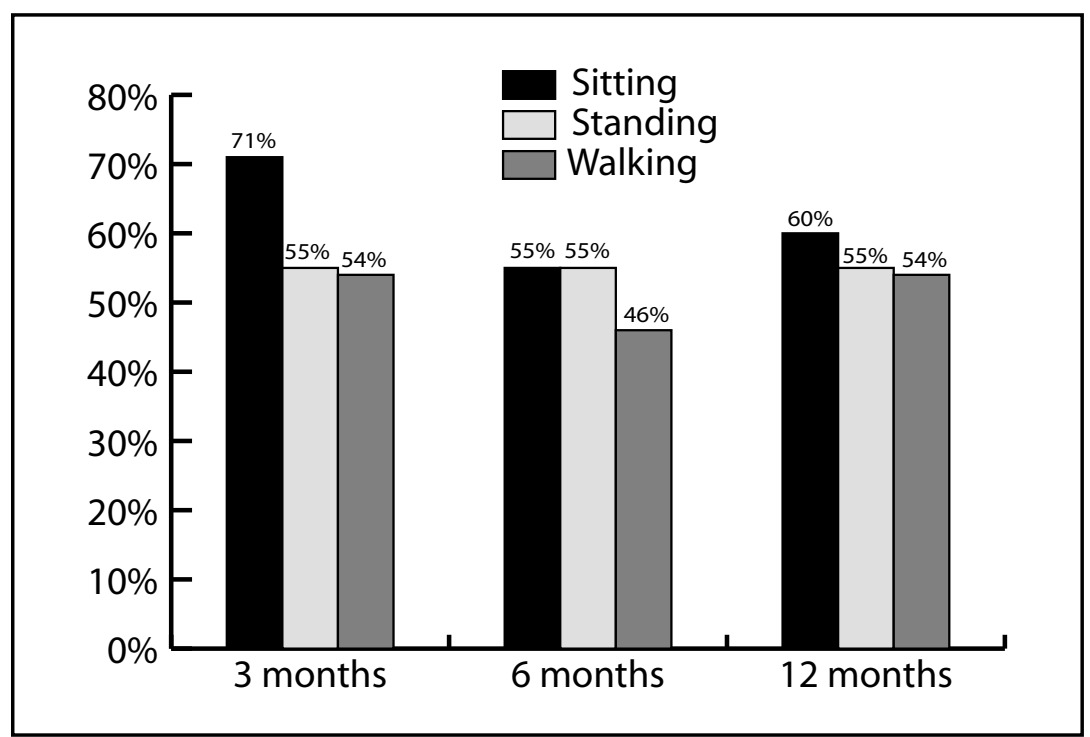

Fig. 3. Illustration of proportion of patients reporting increased functional ability ing research in this field may further elucidate the role of such factors in the reoccurrence of pain.

Coblation ${ }^{\circledR}$ technology was incorporated into the disc decompression field in 2000 , after 4 years of successful use, primarily in the orthopedic field $(32,33)$. In contrast to the thermal surgical techniques used during laser procedures, Coblation achieves molecular disintegration of nuclear material within the disc with significant reduction of heat generation, avoiding thermally damaging vaporization and pyrolysis and reducing collateral damage to surrounding tissues (34). Histological analyses $(35,36)$ and temperature distribution studies $(37,38)$ have been conducted to determine the effects of Coblation on the disc and end-plate during percutaneous disc decompression procedures (Nucleoplasty). Results indicate very little damage or necrosis in surrounding disc tissue or end-plate cartilage with relatively low temperature readings within the disc during the procedure.

Interestingly, patients undergoing cosmetic surgery and tonsillectomies have reported faster healing times when Coblation technology was used instead of laser or conventional techniques $(39,40)$, possibly as a result of reduction in thermal and necrotic damage incurred during the procedure. Additionally, recent research introducing a novel application for Coblation technology in sports medicine suggested that Coblation may have the ability to trigger tissue healing in tendons by increasing their vascularity (41). Further support of the role of Coblation in neovascularization has been indicated through histological observation of increased micro-vessel formation in porcine heart tissue after application (42). A study into the effect of Coblation plasma technology on disc tissue supports the notion that Coblation incites favorable biochemical responses in cytokines in the nucleus of a degenerative disc (43). The healing response observed in this study raises the question of whether plasma discectomy may have efficacy beyond simple disc decompression, with the potential additional benefits of reduced inflammation and tissue regeneration.

A different approach has been utilized in the technique of intradiscal electrothermal therapy or IDET. This is a relatively recent technique targeting the anulus in patients with predominant discogenic back pain related to internal disc disruption with 


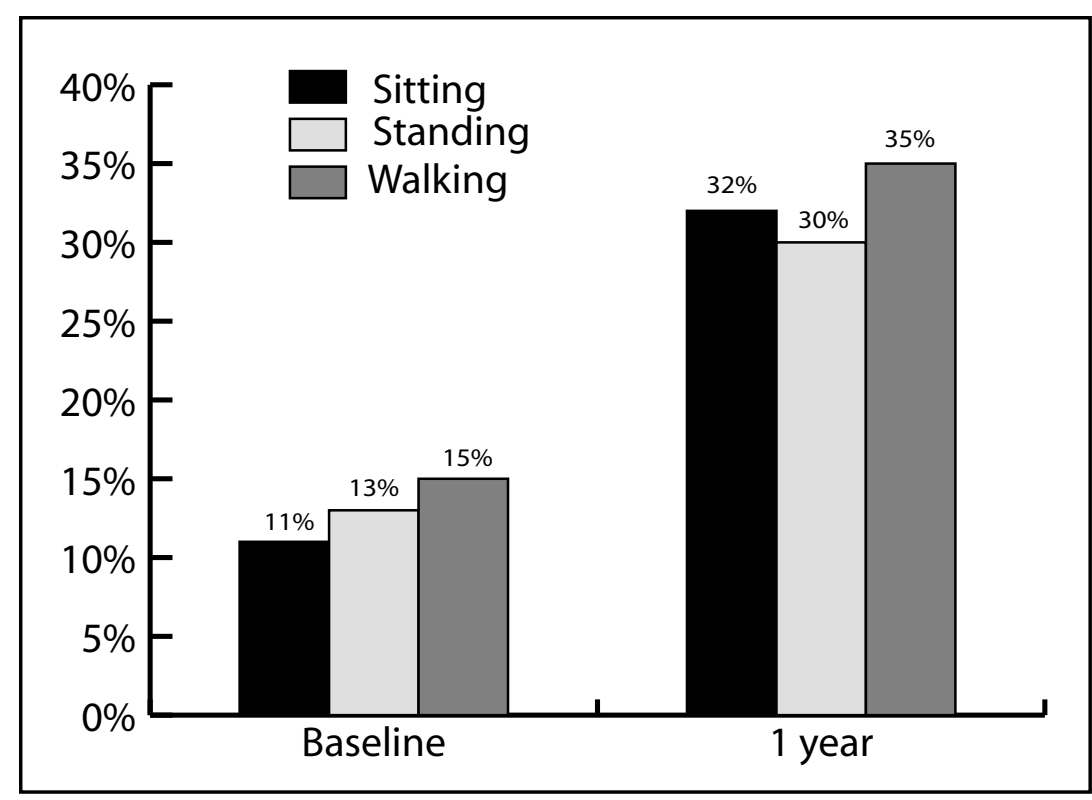

Fig. 4. Comparison of functional increase for sustained activity

reported success rates ranging from 57 to $90 \%$ in non-randomized trials (44-48). A recently conducted randomized, placebocontrolled trial of intradiscal electrothermal therapy in the treatment of discogenic low back pain reported improvements in both control and treatment groups, but with regard to pain, disability and depression, mean improvements were significantly greater in the group treated with IDET. However, although $40 \%$ of patients treated achieved $50 \%$ or more relief of their pain, approximately $50 \%$ experienced no appreciable benefit (48).

Disc decompression procedures have historically been used to treat sciatica symptoms, generally including monoradicular pain, positive root tension sign, and neurologic deficit correlating with disc herniation. Very few studies have been conducted on the use of specific techniques of disc decompression to treat patients presenting with primary back pain due to small disc herniation.

This evaluation may be criticized for its inclusion criteria, non-randomized nature of the study, lack of intent-to-treat analysis, and elimination of data for 10 of the 47 patients with loss of follow-up, and lack of long-term follow-up of greater than 1 year.

Our inclusion criteria were rather strict with patients suffering with only low back pain, with provocative discography based on IASP criteria (26), and failure of conservative management, in- cluding fluoroscopically directed epidural steroid injections. Thus, we have not relied primarily on radiographic findings for determination of pain origin and inclusion in the study. Precision diagnostic injection techniques are considered as an essential addition to the currently available non-invasive diagnostic studies (29, 49-51), as traditional investigations are unable to identify a pain generator in approximately $85 \%$ of the patients. In addition, provocative discography may also confirm or facilitate the accuracy of a pain generator $(52,53)$. Even though discography continues to be controversial (5458 ), other evaluations (59), commentaries (58-61), and reviews $(29,64,65)$ have shown that the evidence for lumbar discography is strong for discogenic pain provided that lumbar discography is performed based on the history, physical examination, imaging data, and analysis of other precision diagnostic techniques.

This evaluation is a prospective case series. While the value of randomized, double-blind trials is well recognized, the importance of prospective evaluations should not be underestimated $(66,67)$. Further, various difficulties and ethical issues involved with randomized trials of interventional techniques are well known and even prohibitive $(68,69)$. Thus, we acknowledge that the results of this evaluation do not provide a definitive answer to the effectiveness of Nucleoplasty for discogenic low back pain, but have value and provide direction for future evaluations.

We also may be criticized for not performing an intent-to-treat analysis, because data were not available for 10 of the original 47 patients. However, because this study was neither randomized or double-blind, we felt that intent-totreat analysis would not be appropriate. We do recognize that intent-to-treat analysis is important in randomized, doubleblind, placebo-controlled trials, so as not to overestimate the response to treatment or underestimate the response to placebo.

Finally, we may be criticized for publishing the results after 1-year follow-up in this evaluation rather than waiting for a 2-year follow-up. Percutaneous disc decompression with Nucleoplasty is a minimally invasive procedure akin to interventional procedures such as intradiscal electrothermal annuloplasty therapy (IDET), etc. Thus, we believe that 1-year followup was appropriate.

We also would like to point out that the degree of annular disruption can have a significant impact on the long-term outcome following disc decompression. During many types of surgical interventions, the method of annulotomy used during the procedure (such as the box or slit incision) diminishes integrity of the disc, leading to a decrease in strength of $40-50 \%$ (70), an increase in severe and early disc degeneration $(71,72)$, and a delay in annular healing (73). Additionally, excessive nuclear tissue removal may lead to accelerated disc degeneration and instability (74-76). Thus, percutaneous disc decompression using a small diameter access cannula, minimizes annular damage.

\section{ConCLUSION}

A cohort of patients with chronic discogenic low back pain, who had failed to improve with at least 3 months of conservative therapies, underwent percutaneous disc decompression using Coblation (Nucleoplasty). Coblation treatment resulted in statistically significant benefit, in terms of pain relief and functional improvement.

\section{ACKNOWLEDGEMENTS}

The authors also wish to thank the editors of Pain Physician for peer review and constructive criticism, which ultimately improved the quality and understanding of the manuscript. 


Author Affiliation
Vijay Singh, MD
Medical Director
Pain Diagnostics Associates
1601 Roosevelt Road
Niagara, Wisconsin 54151
E-mail: vsingh@netnet.net
Chandur Piryani, MD
Pain Diagnostics Associates
1601 Roosevelt Road
Niagara, Wisconsin 54151
Katherine Liao, MD
Pain Diagnostics Associates
1601 Roosevelt Road
Niagara, Wisconsin 54151

\section{REFERENCES}

1. Mirza SK, White AA. Anatomy of intervertebral disc and pathophysiology of herniated disc disease. J Clin Laser Med Surg 1995; 13:131-42.

2. Schwarzer A, Aprill C, Derby R et al. The prevalence and clinical features of internal disc disruption in patients with chronic low back pain. Spine 1995; 20:1878-1883.

3. Manchikanti L, Singh V, Pampati V et al. Evaluation of the relative contributions of various structures in chronic low back pain. Pain Physician 2001; 4:308-316.

4. Guiot B, Fessler R. Molecular biology of degenerative disc disease. Neurosurgery 2000; 47:1034-1040.

5. Macmillan J, Schaffer JL, Kambin P. Routes and incidence of communication of lumbar discs with surrounding neural structures. Spine 1991; 16:167-171.

6. Mixter WJ, Barr JS. Rupture of the intervertebral disc with involvement of the spinal canal. N Engl / Med 1934; 211:210-215.

7. Bogduk N. Nerves of the lumbar spine. In Campbell A (ed.) Clinical Anatomy of the Lumbar Spine and Sacrum, 3rd ed. New York, Churchill Livingstone, 1997, pp 13-32.

8. Adams M. Laboratory model of lumbar disc protrusion: Fissure and fragment. Spine 1994; 19:2015-2017.

9. Postacchini F, Rausching. Anatomy. In Postacchini $F$ (ed.) Lumbar Disc Herniation. New York, Springer-Verlag Wien, 1998, pp 59-79.

10. Carragee EJ, Han MY, Suen PW et al. Clinical outcomes after lumbar discectomy for sciatica: The effects of fragment type and anular competence. J Bone Joint Surg Am 2003; 85A:102-108.

11. Carragee EJ. Indications for lumbar microdiskectomy. Instr Course Lect 2002; 51: 223-228.

12. McDermott DJ, Agre K, Brim M et al. Chymodiactin in patients with herniated lumbar intervertebral disc(s). An open-label multicenter study. Spine 1985; 10:242-
249.

13. Riquelme C, Mustacchio M, Mont'Alverne $\mathrm{F}$ et al. Chemonucleolysis of lumbar disc herniation with ethanol. I Neuroradiol 2001; 28:219-229.

14. Nordby EJ, Wright PH. Efficacy of chymopapain in chemonucleolysis: A review. Spine 1994; 19:2578-2583.

15. Nordby EJ. Diagnosis and patient selec tion. In Brown JE, Nordby EJ, Smith L (eds.) Chemonucleolysis, Vol. 1, New Jersey, Slack Inc., 1985, pp 45-60.

16. Mayer MH, Brock M. Percutaneous endoscopic lumbar discectomy (PELD). Neurosurg Rev 1993; 16:115-120.

17. Onik GM. Percutaneous discectomy in the treatment of herniated lumbar disks. Neuro Clin N Am 2000; 10:597-607.

18. Marks RA. Transcutaneous lumbar discectomy for internal disk derangement: A new indication. South Med / 2000; 93: 885-890.

19. Knight M, Goswami A. Lumbar percutaneous KTP532 wavelength laser disc decompression and disc ablation in the management of discogenic pain. J Clin Laser Med Surg 2002; 20:9-13.

20. Bosacco SJ, Bosacco DN, Berman AT et al. Functional results of percutaneous laser discectomy. Am J Orthop 1996; 25:825828.

21. Pettine KA, Donner EJ. Can percutaneous laser discectomy prevent lumbar fusion? In Proceedings of International Intradiscal Therapy Society, Tenth Annual Meeting, Naples FL, May 1997.

22. Sachs BL, Aparicio RT, Hopkins WO et al. Multi-center patient outcomes of lumbar spinal lase technique: Percutaneous video-endoscopy with holmium laser energy to treat prolapsed lumbar discs. In Proceedings of The International Intradiscal Therapy Society Annual Meeting, Naples, FL, May, 1997.

23. Choy DS, Asher PW, Saddekni S et al. Percutaneous laser disc decompression. A new therapeutic modality. Spine 1992; 17: 949-956.

24. Sharps L, Isaac Z. Percutaneous disc decompression using Nucleoplasty ${ }^{\circledR}$. Pain Physician 2002; 5:121-126.

25. Singh V, Piryani C, Liao K et al. Percutaneous disc decompression using coblation (Nucleoplasty) in the treatment of chronic discogenic pain. Pain Physician 2002; 5 : 250-259.

26. Merskey H, Bogduk N. Classification of chronic pain. In Merskey H, Bogduk N (eds.) Descriptions of Chronic Pain Syndromes and Definition of Pain Terms, 2nd ed. Seattle, IASP Press, 1994, pp 180-181.

27. Chou R, Clark E, Helfand M. Comparative efficacy and safety of long-acting oral opioids for chronic non-cancer pain: A systematic review. J Pain Symptom Manage 2003; 26:1026-1048.

28. Burton CV, Kirkaldy-Willis WH, Yong-Hing $\mathrm{K}$ et al. Cause of failure of surgery on the lumbar spine. Clin Orthop 1981;157:191 199.

29. Manchikanti L, Staats PS, Singh V et al. Evidence-based practice guidelines for interventional techniques in the management of chronic spinal pain. Pain Physician 2003; 6:3-81.

30. Handa T, Ishihara H, Ohshima $\mathrm{H}$ et al. Effects of hydrostatic pressure on matrix synthesis and matrix metalloproteinase production in the human lumbar intervertebral disc. Spine 1997; 22:1085-1091.

31. Ohshima H, Urban JP, Bergel DH. Effect of statis load on matrix synthesis rates in the intervertebral disc measured in vitro by a new perfusion technique. I Orthop Res 1995; 13:22-29.

32. Yetkinler D, Bessette A, Wolozko J. A novel radiofrequency technology (coblation) for dermatologic surgery applications. In Proceedings of BIOS/SPIE Annual Meeting, San Jose, CA, January 2002.

33. Yetkinler D, Lee K, Brandt L, R. Underwood. A novel radiofrequency technology (coblation) for ear, nose and throat surgery applications. In Proceedings of BIOS/SPIE Annual Meeting, San Jose, CA, January 2002.

34. Eggers PE, Thapliyal HV, Matthews LS. Coblation: A newly described method for soft tissue surgery. Research Outcomes in Arthroscopic Surgery 1997; 2:1-4.

35. Chen YC, Lee S, Lehman NL et al. Histology of the disc, endplate, and neural elements post Coblation of the nucleus: An experimental Nucleoplasty study. In Proceed ings of NASS Meeting of the Americas II, New York City, NY, April 2002.

36. Vives M, Manos R, Yuan P et al. The effect of radiofrequency on dural tissue: Histomorphologic analysis. Eur Spine / 2001; 11:417.

37. Chen YC, Lee S. A safety study by obtaining spinal temperature during Nucleoplasty. In Proceedings of ISIS gth Annual Scientific Meeting, San Francisco, CA, September 2001.

38. Yetkinler DN, Nau WH, Brandt LL et al. Disc temperature measurements during Nucleoplasty and IDET procedures. Eur Spine J 2002; 11:418.

39. Hall DJ, Litrtlefield PD, Holtel MR. Radiofrequency ablation versus electrocautery in tonsillectomy. J Otolaryngol Head Neck Surg 2001; 125:158.

40. Kwon HM, Hong BK, Jang GJ et al. Percutaneous transmyocardial revascularization induces angiogenesis: A histologic and 3dimensional micro computed tomography study. I Korean Med Sci 1999; 14:502510.

41. Amiel D. Radiofrequency microdebridement: A novel treatment option for tendinopathies. In Proceedings of The Orthopaedic Research Society's 49th Annual Meeting, February, 2003.

42. Grekin RC, Tope WD, Yarborough JM Jr. et al. Electrosurgical facial resurfacing: A prospective multicenter study of effica- 
cy and safety. Arch Dermatol 2000; 136: 1309-1316.

43. O’Neill CW, Lotz JC, Liu JJ et al. Percutaneous Plasma Discectomy Stimulates Repair in Injured Porcine Intervertebral Discs. In Proceedings of the International Society for the Study of the Lumbar Spine Annual Meeting, May, 2003.

44. Vijay Singh, MD. Intradiscal Electrothermal Therapy: A Preliminary Report. Pain Physician 2000; 3:367-373.

45. Karasek M, Bogduk N. Twelve-month follow-up of a controlled trial of intradiscal thermal anuloplasty for back pain due to internal disc disruption. Spine 2000; 25: 2601-2607.

46. Saal JA, Saal JS. Intradiscal electrothermal treatment for chronic discogenic low back pain: Prospective outcome study with a minimum 2-year follow-up. Spine 2002; 27:966-974.

47. Gerszten PC, Welch WC, McGrath PM et al. A prospective outcomes study of patients undergoing intradiscal electrothermy (IDET) for chronic low back pain. Pain Physician 2002; 5:360-364.

48. Pauza KJ, Howell S, Dreyfuss $P$ et al. A randomized, placebo-controlled trial of intradiscal electrothermal therapy for the treatment of discogenic low back pain. Spine J. 2004; 4:27-35.

49. Fortin J. Precision diagnostic disc injections. Pain Physician 2000; 3:271-288.

50. Boswell MV, Singh V, Staats PS et al. Accuracy of precision diagnostic blocks in the diagnosis of chronic spinal pain of facet or zygapophysial joint origin. Pain Physician 2003; 6:449-456.

51. Bogduk N, McGuirk B. Precision diagnosis. In Bogduk N, McGuirk B (eds.) Medical Management of Acute and Chronic Low Back pain. An Evidence-Based Approach: Pain Research and Clinical Management, Vol. 13. Amsterdam, Elsevier Science BV, 2002, pp 169-176.

52. Ohnmeiss DD, Guyer RD, Hochschuler SH. Laser disc decompression. The importance of proper patient selection. Spine
1994; 19:2054-2058.

53. Colhoun E, McCall IW, Williams L et al. Provocation discography as a guide to planning operations on the spine. J Bone Joint Surg 1988; 70:267-271.

54. Carragee E, Tanner C, Khurana S et al. The rates of false-positive lumbar discography in select patients without low back symptoms. Spine 2000; 25:1373-1381.

55. Carragee EJ, Chen Y, Tanner CM et al. Provocative discography in patients after limited lumbar discectomy. Spine 2000; 25: 3065-3071.

56. Carragee EJ, Tanner CM, Yang B et al. False-positive findings on lumbar discography: Reliability of subjective findings on lumbar discography: Reliability of subjective concordance assessment during provocative disc injection. Spine 1999; 24: 2542-2547.

57. Carragee EJ, Alamin TF, Miller J et al. 2001 Outstanding Paper Award. Provocative discography in volunteer subjects with mild persistent low back pain. Spine J 2002; 2:25-34.

58. Carragee EJ, Alamin TF, Miller J et al. Provocative discography in volunteer subjects with mild persistent low back pain. Spine J 2002; 2:25-34.

59. Manchikanti L, Singh V, Pampati V et al. Provocative discography in low back pain patients with or without somatization disorder: A randomized, prospective evaluation. Pain Physician 2001; 4:227-249.

6o. Wetzel FT. Rates of false-positive lumbar discography: Point of view. Spine 2000; 25:1381.

61. Bogduk N. An analysis of the Carragee data on false-positive discography. ISIS Newsletter, Summer 2001; pp 3-10.

62. Tsou PM. Mislabeling the articles, and then injecting strong bias against lumbar provocation discography as a diagnostic tool. Spine 2001; 26:994-996.

63. Vilims BD, Carragee EJ, Alamin TE. Spine J 2002; 2:387-390.

64. Saal JS. General principles of diagnostic testing as related to painful lumbar spine disorders. Spine 2002; 27:2538-2545.

65. Guyer RD, Ohnmeiss DD. Lumbar discography. Spine J 2003; 3:11S-27S.

66. Concato J, Shah N, Horwitz RI. Randomized, controlled trials, observational studies, and the hierarchy of research designs. N Engl J Med 2000; 342:1887-1892.

67. Benson K, Hartz AJ. A comparison of observational studies and randomized, controlled trials. N Engl J Med 2000; 342: 1878-1886.

68. Lenrow DA, Chou LH. Randomized controlled trials in interventional spine: perils and pitfalls. Pain Physician 2003; 6:8388.

69. Manchikanti L, Heavner JE, Racz GB et al. Methods for evidence synthesis in interventional pain management. Pain Physician 2003; 6:89-112.

70. Ethier DB, Cain JE, Yaszemski MJ et al. The influence of annulotomy selection on disc competence. A radiographic, biomechanical, and histologic analysis. Spine 1994; 19:2071-2076.

71. Ahlgren BD, Lui W, Herkowitz $\mathrm{HN}$ et al. Effect of anular repair on the healing strength of the intervertebral disc: $A$ sheep model. Spine 2000; 25:165-170.

72. Kaigle AM, Holm Sh, Hansson TH. Kinematic behavior of the porcine lumbar spine: A chronic lesion model. Spine 1997; 22:2796-2806.

73. Hampton D, Laros G, McCarron R et al. Healing potential of annulus fibrosus. Spine 1989; 14:398-401.

74. Sortland O, Kleppe $\mathrm{H}$, Aandahl $\mathrm{M}$ et al. Percutaneous lumbar discectomy: Technique and clinical result. Acta Radiologica 1996; 37:85-90.

75. Mochida J, Tos E, Nomura T et al. The risks and benefits of percutaneous nucleotomy for lumbar disc herniation: A 10-year longitudinal study. J Bone Joint Surg Br 2001; 83:501-505.

76. Mochida J, Nishimura K, Nomura $T$ et al. The importance of preserving disc structure in surgical approaches to lumbar disc herniation. Spine 1996; 21:1556-1564. 
